\title{
Limb ischaemia after intra-arterial injection of Temazepam gel: Histology of nine cases
}

\author{
T J Dodd, R N Scott, K R Woodburn, J J Going
}

\begin{abstract}
Aims-To record the histopathological findings associated with intra-arterial injection of Temazepam gel by nine drug misusers.

Methods-Standard histological examination and immunocytochemistry for endothelial markers (factor VIII related antigen, Ulex europaeus lectin) were carried out.

Results-Intra-arterial injection of Temazepam gel may cause severe vascular injury and lead to amputation of fingers or limbs. Histological changes include myocyte necrosis, interstitial oedema, extensive arterial, venous, and capillary thrombosis, and sometimes vasculitis, endothelial swelling, and denudation.

Conclusions-Inadvertent injection of Temazepam gel into arteries may cause catastrophic ischaemic damage, possibly as a result of toxic effects on endothelial cells.
\end{abstract}

$(\mp$ Clin Pathol 1994;47:512-514)

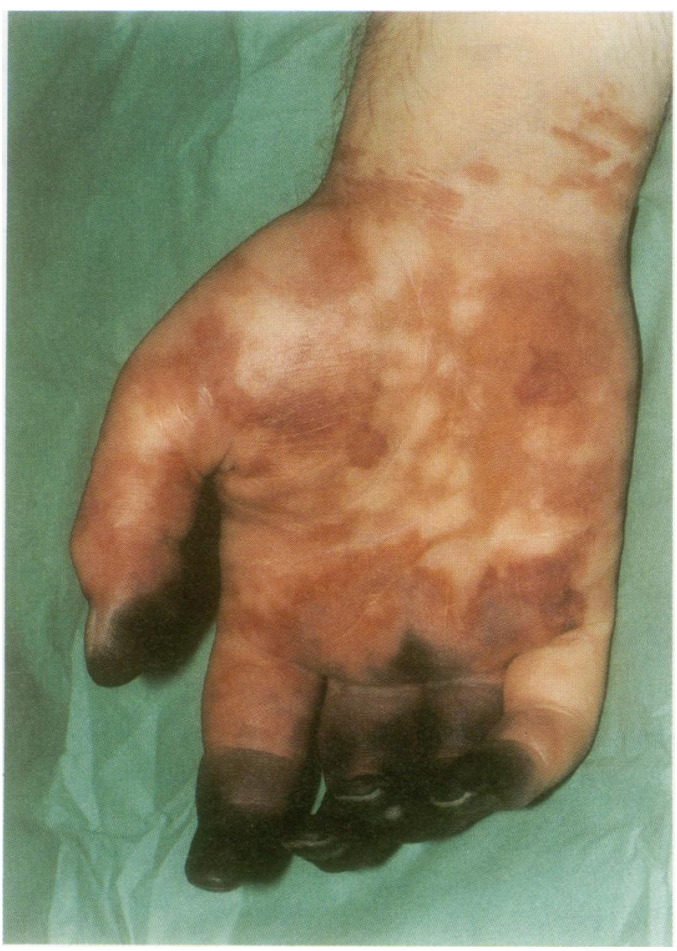

Figure 1 Toxicity of intra-arterial Temazepam (case 9). These gangrenous fingers were subsequently amputated.
Ischaemic necrosis of limbs, leading in some cases to major amputations following intraarterial injection of "solid gel" Temazepam has been reported from several centres in the United Kingdom ${ }^{1-4}$ (figs 1 and 2). In response to previous misuse of Temazepam by injection a new "solid gel" formulation replaced "liquid fill" capsules, ${ }^{5}$ but hopes that this formulation would curtail abuse have been dashed. ${ }^{6}$ Heating the capsule contents with water gives a viscous but injectable product. A similar vascular syndrome has succeeded intra-arterial "liquid fill" injection, ${ }^{6}$ but it seems to be more frequently associated with the gel formulation.

\section{Cases and methods}

Seventeen people were admitted to Glasgow Royal Infirmary after intra-arterial injection of "solid gel" Temazepam during 1991-1992. Of these, 15 had severe reactions. Eleven required multiple fasciotomies for the relief of acute compartment syndromes. Rhabdomyolysis was common, and four patients

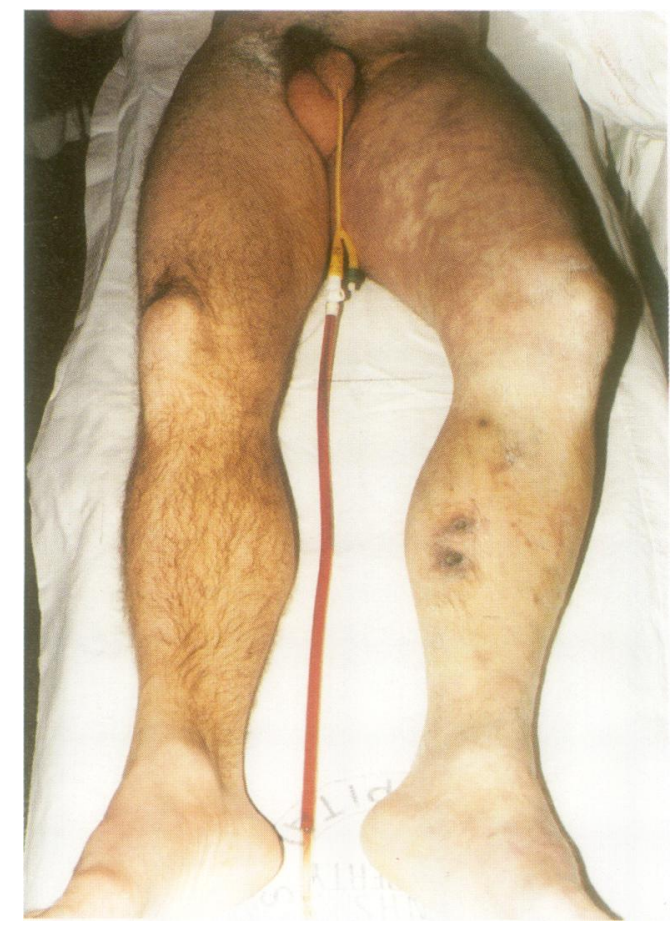

Figure 2 Ischaemic left leg (case 1). The pallor and mottling are characteristic. High above-knee amputation was required. Note myoglobinuria.
Correspondence to: 
Clinical and histological details of patients studied

\begin{tabular}{|c|c|c|c|}
\hline Case No & Age/sex & Clinical events & Histology \\
\hline 1 & $33 \mathrm{M}$ & $\begin{array}{l}\text { Left above-knee } \\
\text { amputation }\end{array}$ & $\begin{array}{l}\text { Arterial and venous thrombosis; } \\
\text { intravascular foreign material; necrosis, } \\
\text { vasculitis }\end{array}$ \\
\hline 2 & $31 \mathrm{M}$ & $\begin{array}{l}\text { Above-elbow } \\
\text { amputation of arm }\end{array}$ & $\begin{array}{l}\text { Arterial and venous thrombosis; necrosis; } \\
\text { vasculitis }\end{array}$ \\
\hline 3 & $23 \mathrm{M}$ & $\begin{array}{l}\text { Fasciotomy } \\
\text { Amputation of toes }\end{array}$ & Arterial and venous thrombosis; vasculitis \\
\hline 4 & $25 \mathrm{M}$ & Fasciotomy-calf & Arteriolitis; viable muscle \\
\hline 5 & $30 \mathrm{M}$ & $\begin{array}{l}\text { Fasciotomy, } \\
\text { renal failure } \\
\text { no amputations }\end{array}$ & $\begin{array}{l}\text { Arterial and venous thrombosis; necrosis; } \\
\text { vasculitis }\end{array}$ \\
\hline 6 & $20 \mathrm{~F}$ & $\begin{array}{l}\text { Fasciotomy, } \\
\text { no amputations }\end{array}$ & Arterial and venous thrombosis \\
\hline 7 & $22 M$ & Fasciotomy-calf & Fibrin thrombi; necrosis \\
\hline 8 & $29 \mathrm{M}$ & Fasciotomy-calf & $\begin{array}{l}\text { Intravascular foreign material, no necrosis } \\
\text { or vasculitis }\end{array}$ \\
\hline 9 & $28 \mathrm{M}$ & $\begin{array}{l}\text { Fasciotomy } \\
\text { right forearm }\end{array}$ & No necrosis or vasculitis \\
\hline
\end{tabular}

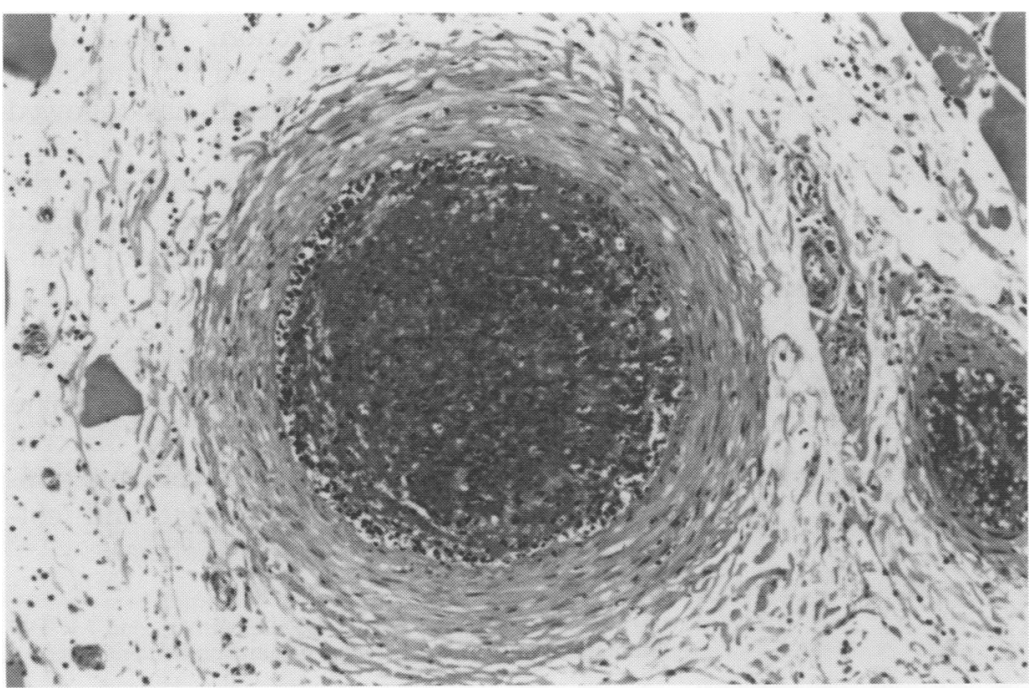

Figure 3 Arterial thrombosis (case 1). Even at this low power there is a suggestion of endothelial swelling.

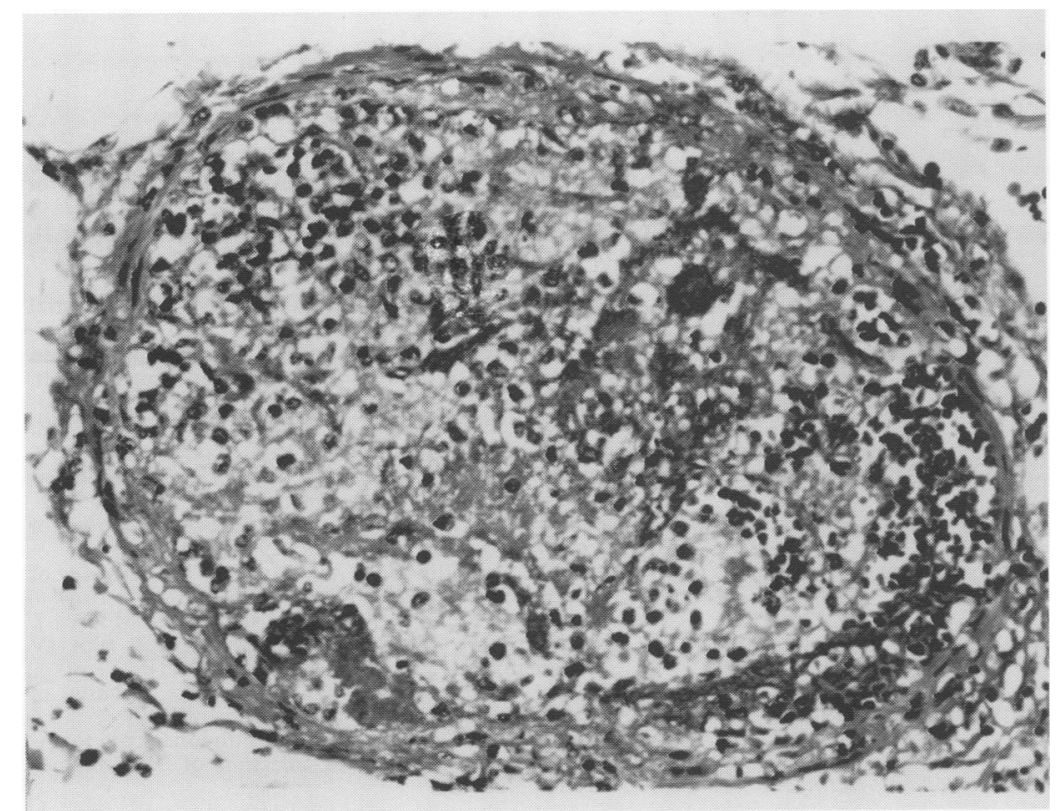

Figure 4 Venous thrombosis (case 1). required haemodialysis for acute renal failure. Three required surgical amputations, including one above-knee and one above-elbow; others had auto-amputated fingers. Tissue was available for histological examination from nine cases and included two amputation specimens and muscle biopsy specimens obtained at fasciotomy.

Standard haematoxylin and eosin sections were examined in all cases, and immunocytochemistry and lectin binding for endothelial cells was also performed (factor VIII related antigen, Ulex europaeus lectin). Tissues were fixed in neutral buffered formalin before examination in view of the history of intravenous drug misuse in all cases.

Examination of the two amputation specimens did not include postoperative angiography, but dissection of the arterial tree was extended into the hand and foot respectively, and multiple cross sections of the dissected vessels were examined at $5 \mathrm{~mm}$ intervals. Representative vascular and muscle blocks were processed for histology (11 from the arm, 20 from the leg). All biopsy specimens (which ranged from 10 to $30 \mathrm{~mm}$ in length) were completely processed for histological assessment.

Histological findings and clinical background are summarised in the table. Cardinal histological features were profound interstitial oedema, arterial and venous thrombosis, capillary thrombosis and very variable degrees of myocyte necrosis (figs 3-5). In five cases there was evidence of vasculitis (fig 5), usually mild but occasionally pronounced. Endothelial cell swelling was occasionally obvious (fig 6). Complete but focal denudation of endothelium was identified in case 1 (fig 7). Sparse exogenous material (in two cases) was of mineral and plant origin. Gel embolism was not identifiable histologically.

\section{Discussion}

The catastrophic vascular syndrome associated with intra-arterial injection of Temazepam gel is more severe than the powder embolism experienced by injecting drug misusers, and simple embolism seems unlikely to be responsible. Temazepam is toxic to vessels. Intravenous injection of a parenteral preparation $(0.5-1 \mathrm{mg} / \mathrm{kg})$ caused moderate or severe pain in 22 of 62 patients, and of 11 patients examined 14 days later, nine had antecubital vein thrombosis. ${ }^{7}$ Severe complications have been described following intra-arterial injection of the liquid preparation. ${ }^{8}$ Launchbury and colleagues have stated that it was impossible to formulate a parenteral preparation of Temazepam which did not cause unacceptable venous damage. ${ }^{9}$

Endothelial damage is perhaps the most plausible explanation for the syndrome. Endothelial swelling identified in some cases is consistent with this. Abnormal permeability of injured vessels could account for the pronounced oedema often seen, and more severe loss of endothelial function for vascular 


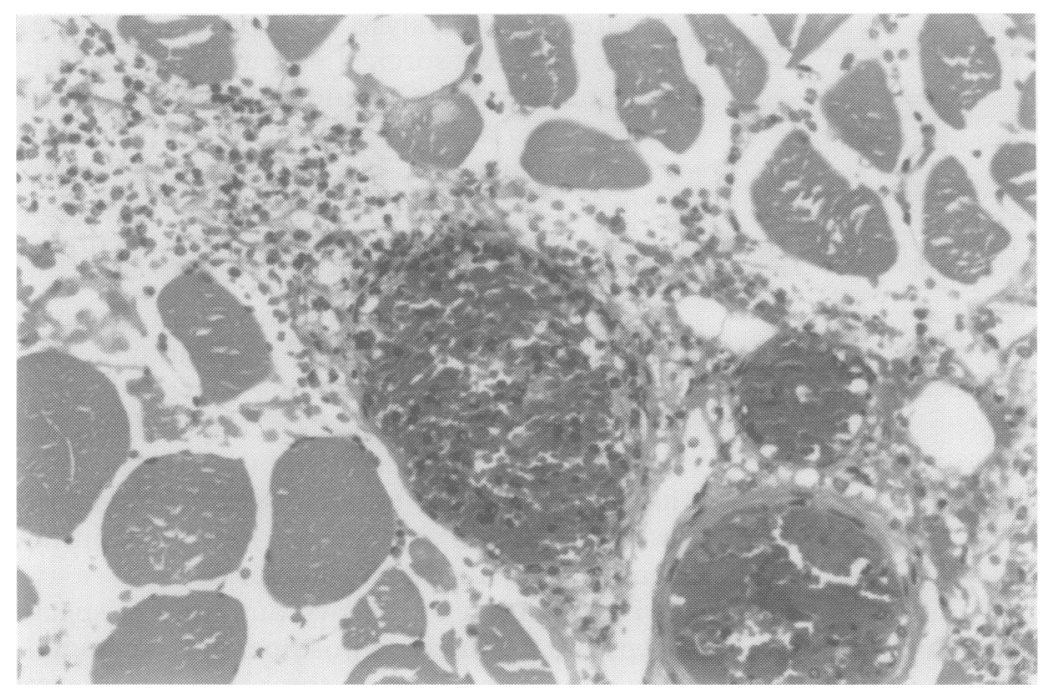

Figure 5 Interstitial oedema, inflammation, and myocyte necrosis (case 1). The wall of the largest vessel is also infiltrated by inflammatory cells.

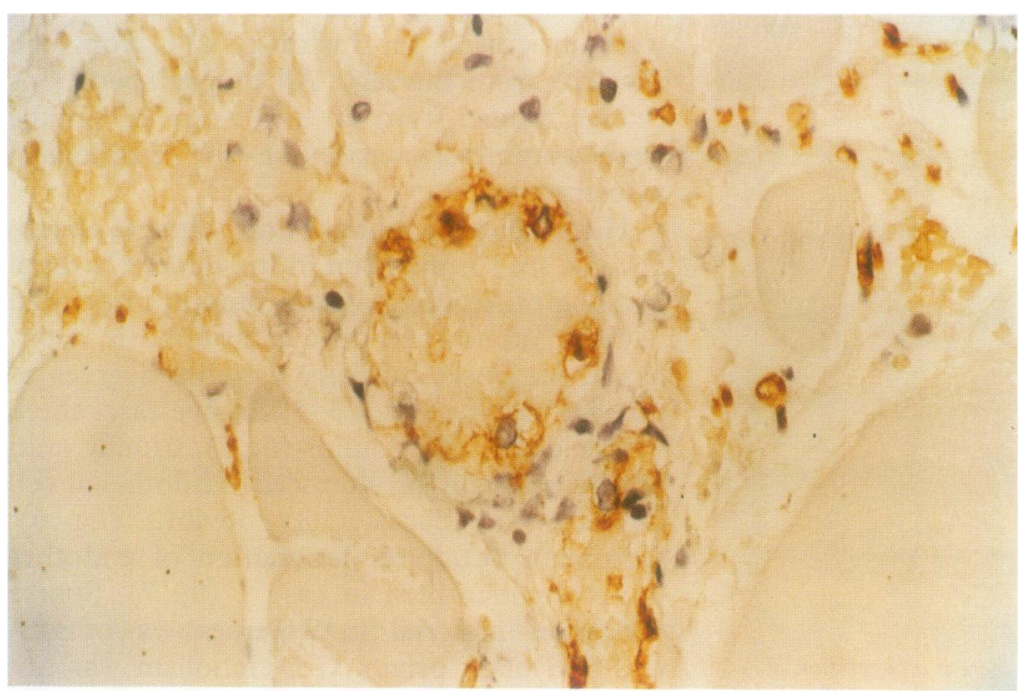

Figure 6 Thrombosed vessel showing pronounced swelling and vacuolation of endothelial cells (case 1; Ulex europaeus lectin).

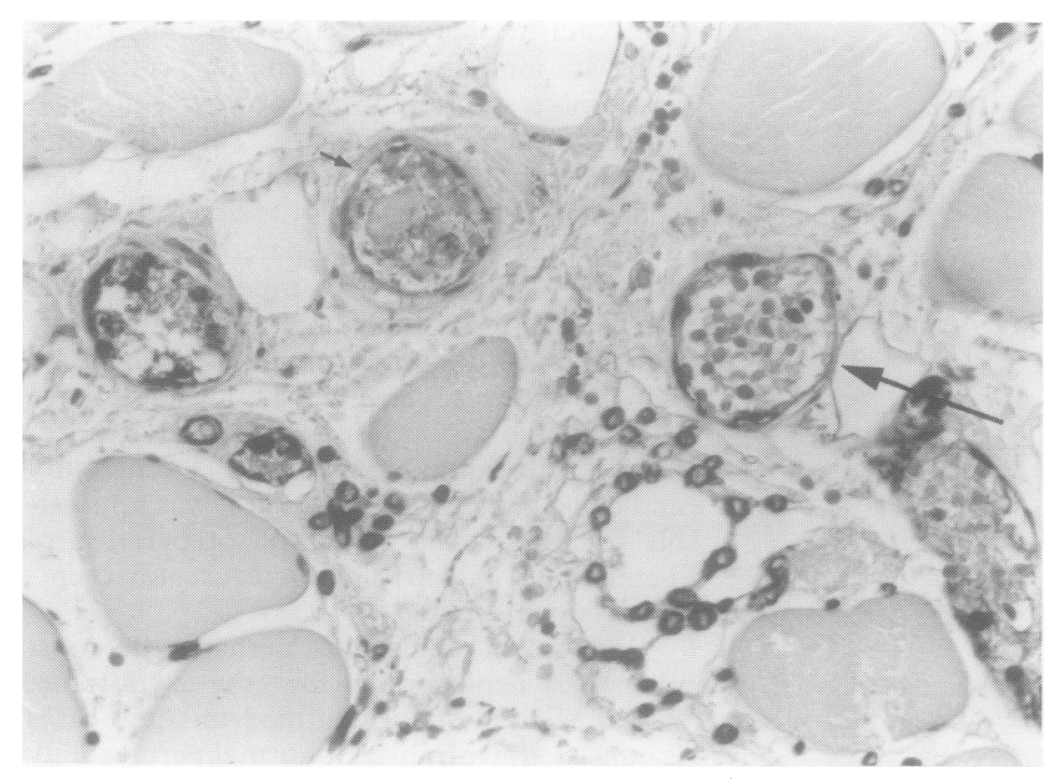

Figure 7 Partial loss of endothelial lining in a venule (case 1; Ulex europaeus lectin). thrombosis. Thus two potent ischaemic mechanisms (increased compartment pressure and vascular thrombosis) potentially contribute to a myocyte necrosis that is sometimes severe. It is not clear why the solid-gel Temazepam preparation should apparently cause more problems than the liquid-filled capsules. Launchbury has pointed out that the macrogol vehicle is water soluble but Temazepam itself is highly insoluble, and would be expected to form an insoluble precipitate when heated with water. ${ }^{9}$ Perhaps this change of state is responsible for the apparent potentiation of toxicity under these circumstances. The vasculitis may reflect nonspecific damage.

The possibility of such a mechanism, and the severity of the toxicity following intra-arterial injection, leads us to wonder about the possible effects of Temazepam solid-gel capsule abuse on the pulmonary vasculature following intravenous injection. Precipitated Temazepam might be retained in, and damage, pulmonary vessels. Death has followed intravenous injection of crushed Temazepam tablets suspended in water; in that case the pulmonary vasculature contained embolised foreign material, but its nature was not established. ${ }^{10}$

If endothelial injury is indeed the major pathogenetic mechanism of this severe adverse reaction, then it may be appropriate for therapeutic interventions to be directed towards modifying endothelial cell function. This strategy was used by Nott and colleagues, ${ }^{4}$ and may have been beneficial.

We thank Mr JG Pollock, Mr DP Leiberman, and Mr DG Gilmour for permission to report patients under their care.

1 Blair SD, Holcombe C, Coombes EN, O’Malley MK. Leg ischaemia secondary to non-medical injection of Temazepam. Lancet 1991;338:1393-4.

2 Scott RN, Wooburn KR, Reid DB, Maraj E, Going J Gilmour DG, et al. Intra-arterial Temazepam. $B M$ 1992;304:1630

3 Adisheshah $M$, Jones DA, Round JM. Intra-arterial Temazepam. BMf 1992;304:1630.

4 Nott DM, Chandrasekar R, Enabi L, Greany M, Bakran A, Harris PL. Intra-arterial injection of Temazepam in Arug abusers. Eur $\mathcal{F}$ Vascular Surg 1993;7:87-9.

5 Drake J, Freedman PS, Hawkins BC, Horth CE Launchbury AP, Whateley-Smith C. Comparative pharmacodynamics of Temazepam Gelthix and liquid-filled soft gelatin capsules. $\mathcal{F}$ Clin Pharm Ther 1991;16:345-51. soft gelatin capsules. f Clin Pharm Ther 1991;16:345-51.
Ruben SM, Morrison CL. Temazepam misuse in a group of Ruben SM, Morrison CL. Temazepam misuse in a group
injecting drug users. Br $\mathcal{f}$ Addict 1992;87:1387-92. injecting drug users. $B r \mathcal{F}$ Addict 1992;87:1387-92.
Hudson MM, Edmonds M, Watkins S. Misuse of Hudson MM, Edmonds M, Wam
Temazepam. BMF 1991;303:993.

8 Halliday NJ, Dundee JW, Carlisle RJT, Moore J, McCafferty JF, Woolfson AD. Experiences with IV Temazepam. Br ₹ Anaesth 1986;58:810P-11P

9 Launchbury AP, Drake J, Saeger H. Misuse of Temazepam. BMF 1992;305:252-3.

10 Vella EJ, Edwards CW. Death from pulmonary microembolisation after intravenous injection of Temazepam BMF 1993;307:26. 